\title{
An Added Perspective on the 2009 SPARTAN and IGAS Report: An Innate Axial Myofascial Hypertonicity
}

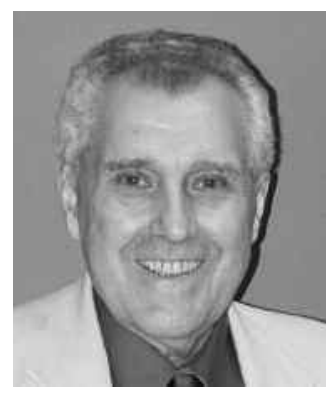

The 2009 Joint Meeting of the Spondyloarthritis Research and Therapy Network (SPARTAN) and International Genetics of Ankylosing Spondylitis (IGAS) members was recently reported ${ }^{1}$. These comments offer a novel hypothesis to complement the progress reviewed in that report. Based upon the characteristic clinical and epidemiological features of ankylosing spondylitis (AS), a structural biomechanical contribution in causation is proposed, namely, an innate axial (spinal) myofascial hypertonicity ${ }^{2,3}$. Such a macro-diathesis would encompass biomechanical models already proposed at micro levels of tissue attachments (entheses) and related sites ${ }^{4,5,6}$. This commentary can only briefly outline biomechanical and clinical reasons for the proposed novel hypothesis in AS, as described ${ }^{2,3,7}$. The hypothesis also incorporates myofascial physiology 7,8 and tensegrity ${ }^{9,10}$ mechanisms in the musculoskeletal system.

Consensus clinical features of $\mathrm{AS}^{1,10,11,12,13}$ suggest that biomechanical influences may be operating at the level of both the body structure and tissue. Excessive physical force (L, fortis, strong) transmissions can be detrimental to both structures and enthesis sites ${ }^{2,5,7}$. The magnitudes of imposed (input) or internal (reactive) forces are influenced by the stiffness of a body or its component tissue attachments ${ }^{5,7}$. Force transmissions become amplified at sites of greater stiffness or resistance and concentrate at transition boundaries (entheses) ${ }^{5,7}$. Further, in mobile systems like the spine, with flexible links, the fusing (or stiffening) of component parts increases the stress concentrations in remaining connections ${ }^{7}$. Such physical principles are consistent with the progression of structural lesions in $\mathrm{AS}^{1,11,12}$. Typically, symptoms and structural pathology begin in the sacroiliac joints (SIJ), which bear the full load of the spine, and subsequently ascend up the vertebral column ${ }^{11}$. The spine and SIJ are complex, integrated, mobile, and load-bearing biomechanical structures ${ }^{2}$.

As indicated in the SPARTAN and IGAS reviews ${ }^{1}$, the onset age, sex, clinical, and pathological characteristics of AS are distinctive features, in addition to its strong genetic susceptibility. The causation of AS is complex and multifactorial ${ }^{1}$. The proposed novel hypothesis was inferred from those characteristic features $1,2,10,11,12,13$, assuming that such expressions would reveal additional clues to underlying pathways.
Onset of AS is notable in adolescent and young adult ages, from age 15 to 35 years, in both sexes ${ }^{1,10,11,12,13}$. About two-thirds of onsets of AS occur in this distinctive range, the mean and median ages of onset being about 23 years ${ }^{14}$. Of note, physical maturation in adolescence and young adulthood naturally strengthens and stiffens the axial (postural and spinal) myofascia in both sexes ${ }^{15}$. Accordingly, patterns of age of onset in AS may in part reflect the natural developmental and maturational changes in axial stiffening ${ }^{15}$ as well as the inherent disease severity risks ${ }^{14}$. Paralumbar muscles can be nearly twice as strong in men as in women, which is also consistent with the overall male preponderance of $\mathrm{AS}^{1,11,12,13,16}$. Females tend to have less syndesmophyte formation and severe spinal deformity than males ${ }^{1,2,11,12,13}$, which may reflect their lesser natural spinal stiffness and strength. In addition, peripheral arthritis in juvenile and adult patients with AS predominates in the lower extremities ${ }^{17}$. That localization could result, in part, from increased impact stresses upon the lower extremities from the greater spinal stiffening ${ }^{15}$.

Personal considerations of biomechanical pathways in AS had evolved over a period of 3 decades ${ }^{13,16}$. Such inferences had led to research and characterization of the subtle and little appreciated polymorphic trait of human resting myofascial tone (HRMT) ${ }^{7,8,18}$. Axial or postural HRMT is an innate polymorphic trait independent of the central nervous system that contributes vitally to postural stability in balanced equilibrium positions ${ }^{7,8,18}$. Increased paralumbar muscle stiffness in patients with early AS was first reported in 1951 by Forestier, et $a l^{19}$, who described this finding as the "bowstring sign" 19 . That observation was subsequently confirmed by palpation and electromyography studies, as reviewed ${ }^{20}$.

Insufficient compared to excessive innate axial HRMT was proposed as the expression of counter-opposing spinal disorders, i.e., adolescent idiopathic scoliosis (AIS) versus AS, respectively ${ }^{21}$. Those conditions have their respective polygenic determinants ${ }^{21}$. As well, genome-wide association studies in Caucasian patients have now been performed $^{1,22,23,24}$, which deserve critical comparison. Indeed, analytical methodology is now available to test if these disorders show inverse associations of single-nucleotide polymorphism alleles ${ }^{24}$. 
Monozygotic twin studies suggest that AS susceptibility has a $90 \%$ or slightly greater genetic inheritance and that HLA-B27 overall has almost half of the genetic association $^{1,22}$. Thus, a comparable degree of association is left to all other non-HLA-B27 combined factors ${ }^{1,22}$. The HLA-B27 gene is found in about $90 \%$ of Caucasian patients with AS, and has a risk ratio of about $100-$ fold $^{22}$. Yet the molecular mechanisms underlying the basis for such an association are not known ${ }^{1,22}$. Neither have the genetic determinants of HRMT polymorphism been determined ${ }^{7,18}$ (PubMed search, 2011), although aging and gender have effects on contractile properties of human skeletal muscle and single fibers ${ }^{25}$.

Of note, HLA-B27 is one of only 2 genetic markers observed to correlate significantly with colder climates in



Figure 1. Theoretical pathways by which osteoproliferative reactions may proceed. both hemispheres ${ }^{26}$. This finding and research on human non-exercise activity thermogenesis (NEAT) ${ }^{27}$ suggested that the HLA-B27 gene was possibly related, in part, to cold climate adaptation and to greater intrinsic energy expenditures by skeletal muscles ${ }^{10}$.

The course, severity, and progression of AS encompass a wide spectrum ${ }^{11,12,13}$. However, burnout (i.e., indefinite remission) rarely occurs ${ }^{28}$. The trajectory of spinal damage in AS may be individualized ${ }^{29}$ and may already be determined at an early disease stage within the host ${ }^{14}$. Current research on genotype and phenotype markers of progression in AS is promising ${ }^{1}$, as is current work in adolescent idiopathic scoliosis ${ }^{23}$.

Anti-tumor necrosis factor therapy has shown significant benefits in reducing inflammation-related measures of AS, but the vertebral osteoproliferative lesions appear to be unabated ${ }^{1}$. Osteoproliferative lesions could be contributed by injury-related pathways, possibly from continuing consequences of excessive stress mechanisms ${ }^{2,3,4,5,6}$. A critical question is if axial myofascial hypertonicity in AS might precede the onset of pain (not stiffness) and inflammatory indicators? A prospective study design has been outlined to investigate this question among high-risk asymptomatic susceptible subjects and matched controls ${ }^{7}$.

In early AS, MRI signal hyperintensities (lesions) are found in the spinal and SIJ bone marrow and at entheses on short inversion time inversion-recovery (STIR) images and on T2-weighted (water molecules) images ${ }^{1}$. In patients with AS, these lesions are usually referenced as inflammatory. However, studies of osteoarthritis ${ }^{30}$ and sports-related injuries $^{31}$ show analogous hyperintensities, but are commonly described as bone marrow edema or edema-like lesions. Those MRI findings are mainly attributed to altered biomechanical/degenerative origins or excessive tissue stresses, rather than being inflammatory. Possible effects of excessive stresses or other biomechanical mechanisms $s^{2,3,4,5,6}$ should be considered in the early MRI changes of AS that progress to osteoproliferative lesions.

This perspective is consistent with current concepts and progress reviewed in the SPARTAN and IGAS report ${ }^{1,22}$. Figure 1 illustrates our proposed added structural biomechanical component to the complex predisposition and course of AS that is novel and that deservies further critical examination. The current perspective of a possible innate mechanical diathesis in AS and the proposed schematic (Figure 1) may reveal theoretical pathways by which osteoproliferative reactions may proceed in this disorder, even though inflammatory mechanisms might be suppressed.

ALFONSE T. MASI, MD, DR.PH, Departments of Medicine and Epidemiology, University of Illinois College of Medicine, Chicago, Illinois, USA

Address correspondence to Dr. Masi; E-mail:amasi@uic.edu 
Supported by the Department of Medicine and The MTM Foundation. Becky Hawkins is acknowledged for her invaluable technical assistance.

\section{ACKNOWLEDGMENT}

Kristina Prus, Brian Andonian, and Mary Jean Dzurisin contributed significantly in composing the schematic image.

\section{REFERENCES}

1. 2009 Joint Meeting of Spondyloarthritis Research and Therapy Network (SPARTAN) and International Genetics of Ankylosing Spondylitis (IGAS). J Rheumatol 2010;37:2604-31.

2. Masi AT, Benjamin M, Vleeming A. Anatomical, biomechanical, and clinical perspectives on sacroiliac joints: an integrative synthesis of biodynamic mechanisms related to ankylosing spondylitis. In: Vleeming A, Mooney V, Stoeckhart R, editors. Movement, stability and lumbopelvic pain: Integration of research and therapy. Edinburgh: Churchill Livingstone; 2007:205-27.

3. Masi AT, Savage LM. Integrated biomechanical influences on ankylosing spondylitis. Spondylitis Plus 2009. Spondylitis Association of America. [Internet. Accessed June 3, 2011.] Available from: http://www.spondylitis.org/research/pdf/ biomechanical_ankylosing_spondylitis.pdf

4. McGonagle D, Stockwin L, Isaacs J, Emery P. An enthesitis based model for the pathogenesis of spondyloarthropathy: additive effects of microbial adjuvant and biomechanical factors at disease sites. J Rheumatol 2001;28:2155-9.

5. Benjamin M, McGonagle D. The anatomical basis for disease localization in seronegative spondyloarthropathy at entheses and related sites. J Anat 2001;199:503-26.

6. Lories RJ, Luyten FP, de Vlam K. Progress in spondylarthritis. Mechanisms of new bone formation in spondyloarthritis. Arthritis Res Ther 2009;11:221.

7. Masi AT, Nair K, Evans T, Ghandour Y. Clinical, biomechanical, and physiological translational interpretations of human resting myofascial tone or tension. Int J Ther Massage Bodywork 2010;3:16-28.

8. Mense S, Masi AT. Increased muscle tone as a cause of muscle pain. In: Mense S, Gerwin RD, editors. Muscle pain: Understanding the mechanisms. Berlin, Heidelberg: Springer-Verlag; 2010:207-49.

9. Ingber DE. The architecture of life. Sci Am 1998;278(1):48-57.

10. Masi AT, Walsh EG. Ankylosing spondylitis: integrated clinical and physiological perspectives. Clin Exp Rheumatol 2003;21:1-8.

11. Borenstein DG, Wiesel SW, Boden SD, editors. Low back and neck pain: Comprehensive diagnosis and management. Ankylosing spondylitis. 3rd ed. Philadelphia: Saunders; 2004:301-26.

12. Braun J, Sieper J. Ankylosing spondylitis. Lancet 2007; 369:1379-90.

13. Masi AT. Do sex hormones play a role in ankylosing spondylitis? Rheum Dis Clin North Am 1992;18:153-76.

14. Brophy S, MacKay K, Al-Saidi A, Taylor G, Calin A. The natural history of ankylosing spondylitis as defined by radiological progression. J Rheumatol 2002;29:1236-43.

15. Masi AT, King JR, Burgos-Vargas R. Novel concepts of severity mechanisms in ankylosing spondylitis. J Rheumatol 2001; $28: 2151-4$.
16. Masi AT, Medsger TA Jr. A new look at the epidemiology of ankylosing spondylitis and related syndromes. Clin Orthop Relat Res 1979;143:15-29.

17. Riley MJ, Ansell BM, Bywaters EG. Radiological manifestations of ankylosing spondylitis according to age at onset. Ann Rheum Dis 1971;30:138-48.

18. Masi AT, Hannon JC. Human resting muscle tone (HRMT): narrative introduction and modern concepts. J Bodyw Mov Ther 2008;12:320-32.

19. Forestier J, Jacqueline F, Rotesquerol J. La spondylarthrite ankylosante: clinique, radiologie anatomie pathologique, traitement. Paris: Masson \& Cie; 1951. [English translation, Desjardins AU. Springfield, IL: Thomas; 1956].

20. Masi AT, Sierakowski S, Kim JM. Jacques Forestier's vanished bowstring sign in ankylosing spondylitis: a call to test its validity and possible relation to spinal myofascial hypertonicity. Clin Exp Rheumatol 2005;23:760-6.

21. Masi AT, Dorsch JL, Cholewicki J. Are adolescent idiopathic scoliosis and ankylosing spondylitis counter-opposing conditions? A hypothesis on biomechanical contributions predisposing to these spinal disorders. Clin Exp Rheumatol 2003;21:573-80.

22. Taurog JD. The role of HLA-B27 in spondyloarthritis. J Rheumatol 2010;37:2606-16

23. Ward K, Ogilvie JW, Singleton MV, Chettier R, Engler G, Nelson LM. Validation of DNA-based prognostic testing to predict spinal curve progression in adolescent idiopathic scoliosis. Spine 2010;35:1455-64

24. Sirota M, Schaub MA, Batzoglou S, Robinson WH, Butte AJ. Autoimmune disease classification by inverse association with SNP alleles. PloS Genetics 2009;5:1-11.

25. Yu F, Hedstrom M, Cristea A, Dalen N, Larsson L. Effects of ageing and gender on contractile properties in human skeletal muscle and single fibres. Acta Physiol 2007;190:229-41.

26. Cavalli-Sforza LL, Menozzi P, Piazza A. The history and geography of human genes. Princeton, NJ: Princeton University Press; 1994:142-5; 307-8.

27. Levine JA, Eberhardt NL, Jensen MD. Role of non-exercise activity thermogenesis in resistance to fat gain in humans. Science 1999;283:212-4.

28. Kennedy LG, Edmunds L, Calin A. The natural history of ankylosing spondylitis. Does it burn out? J Rheumatol 1993;20:688-92.

29. Baraliakos X, Listing J, von der Recke A, Braun J. The natural course of radiographic progression in ankylosing spondylitis evidence for major individual variations in a large proportion of patients. J Rheumatol 2009;36:997-1002.

30. Carrino JA, Blum J, Parellada JA, Schweitzer ME, Morrison WB. MRI of bone marrow edema-like signal in the pathogenesis of subchondral cysts. Osteoarthritis Cartilage 2006;14:1081-5.

31. Hoy G, Wood T, Phillips N, Connell D. When physiology becomes pathology: the role of magnetic resonance imaging in evaluating bone marrow oedema in the humerus in elite tennis players with an upper limb pain syndrome. Br J Sports Med 2006;40:710-3.

J Rheumatol 2011;38:2092-4; doi:10.3899/jrheum.110330 